\title{
Corporate governance e turismo: aplicação ao regime jurídico das entidades regionais de turismo em Portugal
}

\author{
Corporate governance and tourism: application to the legal system of regional tourism entities in \\ Portugal

\section{Virgílio Miguel Rodrigues Machado}

Universidade do Algarve, Escola Superior de Gestão, Hotelaria e Turismo, Largo Engenheiro Sárrea Prado, 8501-859 Portimão, Portugal, vrmachado@ualg.pt

\begin{abstract}
Resumo
A doutrina jurídica e científica sobre sistemas de governo aplicada a organizações de turismo carece de investigação. Estes sistemas, designados internacionalmente como corporate governance, são um instrumento importante para a análise da robustez e eficiência das organizações. 0 regime jurídico português das Entidades Regionais de Turismo, criado pela Lei 33/2013,de 16 de Maio é aqui estudado à luz dos princípios e normas de corporate governance. Conclui-se que o legislador enfatiza vinculações constitucionais de racionalidade técnica e unidade administrativa, mas desvaloriza princípios de descentralização, democracia participativa e autonomia financeira, o que pode afetar a viabilidade de um sistema de governo em organizações de turismo.
\end{abstract}

Palavras-chave: Sistema, Governação, Organização, Triangulação, Turismo.

\begin{abstract}
The legal and scientific doctrine on government systems applied to tourism organizations lacks research. These systems, internationally designated as corporate governance, are important for analyzing the robustness and efficiency of organizations. The Portuguese legal system of Regional Tourism Entities, created by Law 33/2013 of 16 May is here studied in the light of the principles and standards of corporate governance. We conclude that the Law emphasizes constitutional bindings of technical rationality and administrative unit, but devalues the principles of decentralization, participatory democracy and financial autonomy, which may affect the viability of corporate governance in tourism organizations.
\end{abstract}

Keywords: System, Governance, Organization, Triangulation, Tourism.

\section{Introdução. Os conceitos e o problema da} investigação

Entende-se por governo (ou governação) das organizações, o sistema de normas jurídicas, de práticas e comportamentos relacionados com a estrutura de poderes decisórios, incluindo a administração, a direcção e demais órgãos diretivos- e a sua fiscalização (Câmara, 2011).

O problema da governação resulta da investigação dos efeitos da separação entre propriedade e controlo na gestão das grandes empresas (De Falco \& Renzi, 2007) e de entidades de economia social, onde problemas como a percepção do risco e seus limites; os compromissos da organização a médio e longo prazo; os processos de tomada de decisão e a assimetria de informação entre quem representa e quem é representado pela decisão (Medraño, Peñalver, F. \& Peñalver, A., 2013) são críticos na sobrevivência das organizações.

Matérias como a determinação do perfil funcional dos atores organizativos e titulares de órgãos e corpos organizativos ou as relações entre estes e com os titulares do capital, os associados ou fundadores e ainda as relações da organização com todos os sujeitos considerados relevantes para a sua sustentabilidade, os denominados stakeholders, definidos como qualquer grupo ou indivíduo que pode afetar ou ser afetado para a concretização de objetivos organizacionais (Freeman,1984), inserem-se na investigação.

Esta agenda evoluiu para o conceito de corporate governance, tal como fundado nos tempos modernos pelo Relatório Cadbury em 1992 que se dirigiu a sociedades cotadas em bolsa (Câmara,2011), visando expandir critérios de bom governo e boas práticas das organizações, tendentes a melhorar a sua otimização de desempenho, o reforço da capacidade competitiva, a maximização da capacidade de financiamento externo, a salvaguarda da reputação organizacional e a garantia de continuidade das organizações.

Mais tarde, a Organização para a Cooperação e Desenvolvimento Económico (OCDE,2004) considerou o governo das sociedades como "elemento chave para melhorar a eficiência económica e o crescimento, assim como melhorar a confiança dos investidores. O governo das sociedades implica um conjunto de relações entre a direcção da companhia, o conselho de administração, accionistas e o resto dos stakeholders." (p.11).

As exigências de interesse público nesta matéria são reforçadas, seja porque a Constituição da Republica Portuguesa (CRP) prevê a intervenção reguladora do Estado na fundação de organizações tão distintas como as associações públicas, as fundações públicas e as empresas públicas (respectivamente, art.ํㅗ 165oํo 1 alínea s) e u) da CRP), seja porque existe uma obrigação de eficiência do sector público, enquanto incumbência prioritária do Estado no domínio económico e social (art.o 81o alínea c) da CRP).

A investigação científica da análise jurídica de corporate governance em turismo tem tanto de inefectividade, como de necessidade, dada a importância reconhecida dos efeitos das práticas de bom governo no desenvolvimento local e territorial, criação de emprego estável e de qualidade, integração social (Medraño et al., 2013) e ainda de criação e manutenção de relações de confiança, através de organização de redes sociais e reforço de mecanismos de democracia participativa em organizações públicas de turismo (Brandão, Baldi \& Alban, 2014). 
Todavia, tal investigação levanta dificuldades, dada a natureza híbrida do turismo (Py, 1996; Fernández, Jimenéz \& Menéndez, 2004; Machado, 2010), em que confluem, com complexidade, relações e interesses jurídicos de diversa ordem ou natureza; públicos, centrais, regionais e locais; privados, empresariais, profissionais ou coletivos, carecendo todas de uma envolvência regulatória organizacional que antecipe, planeie e controle uma actividade marcada por uma forte incerteza e variabilidade do seu ambiente externo (Giotart \& Balfet, 2007).

As Entidades Regionais de Turismo (RT) foram instituídas pela Lei 33/2013, de 16.05.2013, adiante designada LRT, ao abrigo da competência legislativa atribuída pelo art.ำ $161^{\circ}$ alínea c) da CRP à Assembleia da República (AR). 0 art.o $165^{0}$ no 1 alínea s) permite também à AR a regulação de associações públicas.

Todavia, a RT é apresentada como uma pessoa colectiva pública, de natureza associativa (art. ${ }^{0}$ o da LRT). Por imperativo constitucional (art.․ 267ํำ $\mathrm{n}-4$ da CRP), as associações públicas só podem ser constituídas para a satisfação de necessidades específicas. A LRT não apresenta preâmbulo justificativo da sua criação, limitando-se a revogar (art.o 45o alínea a)) o D.L. no 67/2008, de 10.04.2008, que instituía o regime anterior das RT.

A CRP (art.o 267.ํำ 4) impõe ainda às associações públicas uma organização interna baseada no respeito dos direitos dos seus membros e na formação democrática dos seus órgãos. Importa verificar se a LRT respeita também estas vinculações constitucionais.

A LRT constitui uma organização privilegiada para um estudo de corporate governance, dada a confluência de interesses em órgão colegial deliberativo (Estado, municípios e entidades privadas, entendidas com interesse no desenvolvimento e valorização turística na respetiva área (art.o $12^{\circ}$ n ${ }^{\circ} 1$ alíneas a), b) e c)). Esta enunciação de interesses privados oculta reais capacidades de influência e intervenção na gestão do poder das organizações públicas.

As suas atribuições são, por um lado, institucionais e territoriais na colaboração na definição da política nacional de turismo e de elaboração de planos regionais de turismo

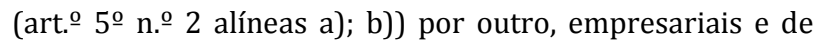
prestação de serviços na promoção e informação turística (art.o 5o no 2 alíneas d) e) e f)), pelo que será importante verificar a robustez da organização para o desempenho de missões tão distintas.

Esta duplicidade, numa perspectiva sistémica, apresenta problemas. A LRT prevê diversas remissões para regimes subsidiários aplicáveis. Do Código do Procedimento Administrativo (CPA) aplicável subsidiariamente à composição, organização e funcionamento dos órgãos das

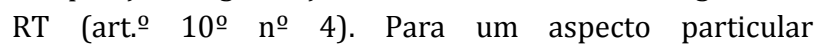
(remuneração do fiscal único-art.o $21^{\circ} \mathrm{n}^{\mathrm{o}}$ 4), é feita remissão para a Lei-Quadro dos Institutos Públicos (LQIPLei 3/2004, de 15.01.2004).

Na verdade, a natureza institucional das atribuições das RT poderia remeter regime jurídico subsidiário para a LQIP. Ou, dada a natureza empresarial, para a Lei do Sector
Empresarial do Estado, constante do D.L. no 133/2013, de 3.10.2013 (LQEP). A LRT é omissa.

O que dificulta a análise da LRT em quadros contextuais e sistémicos mais amplos de investigação quanto a princípios gerais de organização, criação e acto estatutário, órgãos e serviços, gestão económica e financeira e de acompanhamento, avaliação de desempenho e fiscalização.

Os problemas da investigação estão colocados. Que natureza tem a RT? A que vinculações jurídicoconstitucionais está adstrita? Para o bom governo da RT a que princípios e regras jurídicas gerais de governação podemos apelar? As dos institutos públicos, dada a sua vocação institucional? As das empresas públicas, dada a vocação empresarial ou de prestação de serviços? Ou de um terceiro género, atendendo à natureza especial do regime jurídico da RT? As opções seguidas estão conforme princípios e boas práticas de corporate governance? Vejamos a metodologia.

\section{Metodologia de investigação.}

A metodologia primará pela utilização do método jurídico de interpretação das leis, em primeiro lugar, segundo o elemento histórico, centrada na história legal da RT para se descortinar a sua natureza e identidade. Reforçando a análise com a perspectiva da doutrina e a história e conjunturas sociais (occasio legis) determinantes da feitura da norma.

Depois, o recurso ao elemento sistemático (Pereira, 2007), utilizando uma perspectiva holística e integrada de uniformização de vinculações jurídicas às organizações instituídas por vontade normativa pública (institutos públicos, empresas publicas) que tenham um substrato, ora institucional, ora empresarial, na sua constituição e finalidade.

Tal perspectiva permitirá identificar métodos estruturais, teleológicos e funcionalistas, próprios da Ciência do Direito (Gabardo, 2003), que permitam descortinar o porquê e o para quê das organizações com identificação de tensões construtivas entre diversos titulares de interesses nessas organizações.

Utilizando-se uma metodologia qualitativa de triangulação, própria das Ciências Sociais (Decrop, 2004), serão identificados três pólos de interesses específicos na organização, a saber:

a) Os interesses do Estado;

b) Os interesses das entidades associativas públicas;

c) 0 s interesses das entidades associativas privadas;

O método da triangulação supõe uma combinação triangular de órgãos administrativos, de fiscalização e consultivos, tendo em vista a obtenção de um alinhamento de posições dos órgãos da pessoa coletiva no seu conjunto quanto a alguns elementos fundamentais (ex: planos, orçamentos, contas), incentivando comunicação e informação, em suma, linhas de força comuns entre os órgãos.

Assim, a investigação constitui um exercício de otimização estrutural, de coerência entre objetivos externos e 
incentivos internos, de centralidade, à captura de valor, pelo Direito, para a organização RT em ordem a, segundo a referida perspectiva triangular, se detetarem alinhamentos de processos (Pavlovich, 2003), coerência de relações entre agentes, com a formulação de padrões, contrariando perdas ou excessos de aplicação de recursos (Clarke, 2004) e criação de padrões de interacção e troca de informação (Saixena, 2005), que induzam confiança e valor no compromisso de sustentabilidade e bom governo da organização.

\section{A Natureza Jurídica das Entidades Regionais de Turismo}

A representação dos órgãos locais e regionais de turismo coube, historicamente, quase sempre, a representantes de várias administrações públicas (local e central) e representantes de vários interesses privados (art.ํㅜㅇㅡ da Lei no 1152, de 23.04.1921 - Comissões de Iniciativa; art. ${ }^{\circ} \mathrm{S}$ $122^{\circ}$ e $126^{\circ}$ do Código Administrativo de 1940, aprovado pelo D.L. no 31095,de 31.12.1940 -zonas de turismo).

A natureza regional e territorial destas entidades esteve na base de uma história (Torres, 2003; Machado,2010) que se centrou em vários regimes jurídicos, uns de pendor municipal e descentralizador (D.L. 437/82, de 16.08.1982); outros de carácter mais centralizador (D.L. 67/2008, de 10.04.2008), o que consolidou a dependência financeira dos órgãos regionais de turismo em relação à Administração Central.

Esta representação plúrima, uma espécie de composição plural de interesses associativos público-privados, espelha bem a dificuldade jurídica de enquadrar estes organismos da administração pública numa categoria bem definida. Moreira (2002; 2005) defendeu inicialmente a sua natureza como "consórcios públicos" (2002, p. 362); depois, como "organizações híbridas", simultaneamente, administração regional do Estado e administração municipal (2005, p.38).

A doutrina (Miranda, 1988, p. 73) qualifica as regiões de turismo como "associações públicas do poder local". No mesmo sentido, o parecer no 131/93, da Procuradoria-Geral da República publicado na II série do D.R. de 23.11.1993, qualifica-as como "associações públicas de municípios de tipo especial, formadas na base da cooperação com o Estado".

Verificam-se, historicamente, hesitações do legislador na identificação e caracterização da natureza jurídica das RT e consequente enquadramento em regimes e princípios mais amplos.

A LQIP caracterizava as RT como institutos públicos de regime especial (art.o 48o alínea d). Esta disposição foi revogada pelo Decreto-Lei no 5/2012, de 17.01.2012, sem justificação. A natureza associativa das RT é assumida na LRT (art.․ 4ํㅜ), sem que se diga expressamente que é uma associação pública.

Na verdade, o termo "regional" tem um cunho significativo territorial no âmbito da natureza das RT. O legislador (art.o 3 oํ 1) prevê a existência de cinco RT, correspondente às áreas regionais definidas para as unidades da NUTS II
(Nomenclatura das Unidades Territoriais para Fins Estatísticos).

Dir-se-á que as RT se enquadram nos objetivos gerais de eficácia da Administração Pública no planeamento e promoção turística do país com a sua divisão por regiões e não na satisfação de necessidades públicas específicas, pelo que aqui não existe correspondência com a vinculação prevista no art. ${ }^{267 ㅇ ㅡ ㅇ ㅡ ~} 4$ da CRP.

Segundo Farinho (2011), dir-se-ia que existe "uma tensão dilacerante e oscilante entre os conceitos de Instituto Publico e Associação Pública nas RT" (p. 592), o que pode implicar uma natureza e caracterização desta organização como um tertium gens (terceiro género) de regime variável conforme conjunturas, vontades políticas diversas de sucessivos governos e legislaturas, com consequências desfavoráveis para o seu sistema de governação.

Esta conclusão tem importância para a boa ou má governação de organizações de turismo. Para Giotart et al. (2007, p. 166), estas devem assegurar alguma durabilidade, pela perenidade de estruturas, pela normalização de processos. Burns (2004, p. 36) afirma que o consenso, na base do planeamento turístico, pressupõe acordos de longo prazo ou de pré-planeamento.

A padronização de consensos que possibilitem troca de experiências, padrões de troca de informação, monitorização e medida dos resultados com alinhamento de objetivos, confiança e colaboração entre agentes intervenientes nos processos de planeamento e desenvolvimento é fundamental em turismo, para redução da incerteza e complexidade que caracteriza o ambiente fragmentário e compósito da produção turística.

Neste sentido, dispõe o artigo 8. da LRT, sob o princípio da estabilidade, que as entidades que participem nas entidades regionais de turismo ficam obrigadas a nelas permanecer por um período mínimo de cinco anos, sob pena de devolução e perda de todos os benefícios financeiros e administrativos atribuídos ou a atribuir no âmbito da referida participação.

Importaria que os contratos-programa, operativos e funcionais no financiamento das RT também tivessem essa estabilidade e longa duração, o que não é previsto. Igualmente para a estabilidade das receitas seria importante a obtenção de receitas próprias ligadas autoreferencialmente às receitas turísticas geradas na região.

A natureza associativa das RT está presente na LRT. A Assembleia Geral (AG) tem um substrato associativo baseado na representação de interesses do Estado, municípios e entidades privadas (art.․ 12ำ no 1), não devendo estas últimas ultrapassar o número de municípios participantes (art.o $12^{\circ}$ no 4 ).

As entidades privadas devem assegurar a representação de interesses distintos, nomeadamente, setor do alojamento, restauração, agências de viagens, empresas de animação, transportes, operadores turísticos, sindicatos, em conformidade com o que vier a ser definido nos estatutos da RT (art. ${ }^{12}$ 으은). 
É a AG que elege a maioria dos membros da Comissão Executiva (CE), seja, três de cinco (art.o 13o alínea b) e 15응 no 1 da LRT), feita mediante lista, que deve incluir a indicação do membro da comissão executiva que exerce as funções de presidente (art.o 15o no 2). Elege ainda a totalidade dos membros do Conselho de Marketing (art.

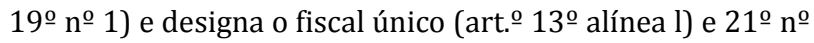
2 da LRT), sob proposta da Comissão Executiva.

É a AG que aprova os projetos de estatutos e suas alterações, sob proposta da comissão executiva, a submeter ao membro do Governo da área do turismo e que aprova os regulamentos internos, sob proposta da $\mathrm{CE}$, incluindo o regulamento relativo ao pagamento de quotas pelas entidades participantes, que aprova o plano de atividades e o orçamento anuais, sob proposta da CE e ainda os documentos de prestação de contas (art.ํㅗ 13ํo alíneas e) e h) da LRT).

Todos estes poderes da AG de suporte associativo e de representação institucional configuram-nas como associações públicas de planeamento e promoção turística através de uma cooperação, contrato organizacional entre o Estado, municípios e entidades privadas num determinado território em conformidade com a doutrina antecedente. Esta natureza contratual traduz mais fragilidades do que fortalezas em sede de corporate governance.

Consequentemente, estão sujeitas à vinculação constitucional do art. ${ }^{\circ} 267^{\circ}$ no 4 da CRP quanto a princípios de formação democrática dos seus órgãos e de respeito dos direitos dos seus membros. Estes deveres estão respeitados na LRT no método de eleição para a escolha da maior parte dos representantes dos órgãos, inexistência de regimes de sanções disciplinares específicos e aplicação das regras subsidiárias do CPA (D.L. 4/2015, de 07.01.2015) que não exigem, à partida, maiorias qualificadas para as

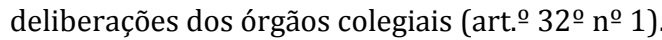

\section{O Corporate Governance das Entidades Regionais de Turismo}

O corporate governance procura um tratamento jurídico e científico uniforme para os problemas da governação organizativa (Câmara, 2011). A governação pode ser desenvolvida através de múltiplas ferramentas (estatutos, códigos de conduta, normas jurídicas em sentido próprio), mas a sua funcionalidade é vista como uniforme (Lomba \& Lino, 2011; Antunes, 2011; Oliveira,2011).

O corporate governance tem como objetivos a procura de fórmulas organizativas robustas, eficientes e aptas a assegurar a profissionalização da gestão, maximização do desempenho e a fazer cumprir o interesse público na realização do objeto social.

Princípios importantes como a prestação de informação anual sobre a governação, deveres de lealdade e cuidado na administração, dupla fiscalização, pública e privada, transparência de processos, incentivos e remuneração a um bom desempenho, avaliação e controlo pelos titulares de interesses na organização constituem referenciais fundamentais da investigação em corporate governance.
Em Direito do Turismo, a perspectiva desenvolvida pelo corporate governance apresenta-se de particular utilidade. A sua natureza híbrida, em que confluem interesses públicos e privados, prosseguidos, muitas vezes, em concertação, contratação formal ou informal numa perspectiva organizacional aconselha uma perspectiva transversal e homogeneizadora (público-privada) para a sua investigação.

Quando organizações como as RT são criadas por lei para tutela de interesses (planeamento e promoção turística de territórios), assumidos como cooperativos (através de recursos partilhados ou afetos a fins comuns), sendo geridos por organizações em que a vontade é também codeterminada, ou pelo menos, fortemente condicionada por uma pluralidade de interesses público-privados, o corporate governance surge como ferramenta de extraordinário interesse e acuidade para análise de sua eficiência e robustez.

Esta perspectiva é sustentada nas vinculações da Constituição, em especial, da obrigação de zelo do Estado em assegurar a eficiência do sector público (art.o 81ํo alínea c) da CRP); a eficácia e unidade da acção administrativa e a racionalidade dos meios a utilizar pelos serviços (art.․ 267음 no 2 e no 5 da CRP) no que dir-se-ia, os mesmos princípios seriam perfeitamente aplicáveis a qualquer organização privada.

Igualmente, a procura de qualidade de regulação de organizações que têm um elemento associativo relevante no seu substrato é uma obrigação do Estado Português assumida no memorando de entendimento com o BCE/FMI/UE em 17.05.2011. (acessível em http://www.portugal.gov.pt/media/371372/mou_pt_2011 0517.pdf)

Tal memorando prevê nos pontos 3.42 e 3.43 a regulação, por lei, da criação e funcionamento de associações criadas pela Administração Central e Local, bem como a definição de mecanismos de monitorização e reporte e de avaliação e desempenho, pelo que se entende serem estas vinculações, por um lado, uniformes; por outro, constituindo padrões, numa perspectiva sistemática e de corporate governance, de análise de LRT.

Os pontos 3.42 e 3.43 "Dos objetivos de Medidas orçamentais estruturais", visam a melhoria da eficiência da administração pública; reorganização serviços; regulação de criação e o funcionamento de todas as entidades públicas e melhoria do processo orçamental através do enquadramento legal geral para reforçar a gestão de riscos, a responsabilização, o reporte e a monitorização.

$\mathrm{Na}$ utilização do método histórico na investigação, verificaremos que a LRT está comprometida com os objetivos do memorando, constituindo vontade conjuntural determinante na sua feitura.

Desejável, em termos de corporate governance e, de acordo com estes compromissos, seria a criação de uma Lei-Quadro de Associações Públicas Territoriais, à semelhança das Associações Públicas Profissionais (Lei 2/2013, de 10.01.2013). 
Analisamos, à luz dos princípios de corporate governance, o regime da LRT. Nesta, o modelo de comissão executiva (CE) é o adotado para o órgão de administração e gestão (art.o $16^{\circ}$ no 1 e no 2), mas em que, atendendo à sua periodicidade de

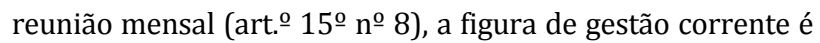

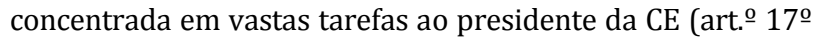
nos 1 alíneas a) a u)), a quem lhe compete praticar todos os atos necessários ao normal funcionamento da RT no âmbito da gestão dos recursos humanos, financeiros, materiais e patrimoniais (art. $\stackrel{0}{17} \stackrel{0}{0}$ no 1 alínea d).

A competência de fiscalização é conferida a um fiscal único que é o órgão responsável pelo controlo da legalidade, da regularidade e da boa gestão financeira e patrimonial das RT. Compete-lhe, designadamente, verificar as contas anuais; emitir o certificado legal de contas; verificar a regularidade dos livros, registos contabilísticos e documentos que lhe servem de suporte e emitir parecer sobre as contas do exercício, nomeadamente sobre a execução orçamental, o balanço e a demonstração de resultados (art. $21^{\circ}$ nํㅜ 1 e 22ํáneas a) a d) da RT).

Importaria considerar, para robustez das funções de controlo, um mecanismo de dupla fiscalização, para além do fiscal único, através de um órgão consultivo técnico, por exemplo, composto por representantes dos municípios, Conselho de Marketing e Estado.

A LQIP (art.ํ 17ำ noํ 1 a 3) dispõe sobre a previsão de órgãos consultivos em determinadas matérias. 0 que permite também possibilidade de dupla fiscalização ao órgão administrativo, reforçando deveres de cuidado e de lealdade por parte dos seus titulares na gestão da entidade pública. Nada se prevê na LRT.

0 alinhamento é estimulado através de elementos comuns (ex: planos, orçamentos, contas) de informação entre órgãos e deveres de cooperação reforçados. Este tipo de mecanismos ajudaria a viabilidade de organizações que se baseiam na complementaridade de atuações entre entidades públicas, centrais e locais e com entidades privadas, próprios da natureza associativa das RT. A LRT é omissa.

Este modelo triangular não tem sequência na LRT. Prevê-se um órgão, de natureza consultiva (o Conselho de Marketing$\mathrm{CM}$ ), em que as competências se destinam principalmente à aprovação e acompanhamento da execução do plano de marketing proposto pela CE (art. ${ }^{\circ} 18^{\circ} \mathrm{n}^{\mathrm{o}}$ 1) e pareceres (em que o regime não estabelece natureza vinculativa), em certos assuntos (criação e extinção de postos de turismo, estratégias de marketing), sob solicitação da CE.

A maioria dos membros do CM deve ser constituída por representantes do tecido empresarial regional, ou seja, do sector privado, como tal reconhecidos pela Confederação do

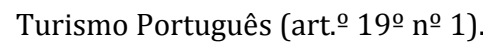

A criação de um órgão especializado em determinados assuntos, de natureza consultiva, mas sem capacidade de emitir pareceres vinculativos sob esses assuntos ou que dá aprovação a um acto por outro órgão (Comissão Executiva) que tem menor competência especializada que o próprio órgão consultivo, confunde a natureza do órgão e não cumpre objetivos de profissionalização de gestão, racionalidade técnica e eficiência vinculativas da atuação da Administração (art.o 81o alínea e) e $267^{\circ}$ no 5 da CRP), não constituindo uma boa estruturação de sistema de governo das RT.

Propor-se-ia, na perspectiva triangular atrás referida, que o plano de marketing fosse proposto pelo $\mathrm{CM}$ e que fosse precedido, numa perspectiva de dupla fiscalização, pelo parecer favorável de um Conselho Consultivo, a criar, e do fiscal único tendo em vista sua aprovação pela Assembleia Geral (AG), antes de ser executado pela CE.

Tal reforçaria os referidos objetivos de eficiência e racionalidade atrás assinalados, mas também de transparência e democracia participativa dos próprios interessados (stakeholders) na formação das decisões que lhes disserem respeito (art. 오 $267^{\circ}$ no 4 e 5 da CRP), que estão na base da génese da Administração Autónoma, seja territorial ou não territorial (Moreira, 2002).

A profissionalização da gestão compromete-se ao não se atribuir qualquer remuneração, despesas de representação ou outros benefícios aos membros do Conselho de Marketing (art.ํ 19 n 5 da LRT), não sendo remunerados os cargos de membros da CE, tão só dos cargos de Presidente e Vice-Presidente (art.o 15 ํo 5). Importa, ainda, tecer algumas considerações quanto à intervenção e representação do Estado na triangulação composta pela deliberação, administração e fiscalização da RT.

A intervenção do Estado na AG é mais importante do que, à primeira vista, se deduz. Na verdade, prevendo a LRT uma equiparação de número de membros de municípios e representantes de entidades privadas na composição da $A G$

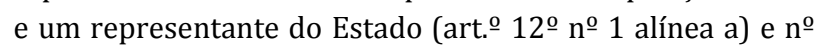
4), este pode ter, pelo seu voto, a capacidade de gerar maiorias. Como? Em combinação com os representantes dos municípios ou das entidades privadas, e, alternativamente, em cada contexto mais favorável aliando-se a uns interesses contra outros, podendo assegurar as maiorias necessárias às deliberações da AG.

Pergunta-se se este modelo assegura princípios de democracia participativa e de auto- governo. Mais se questiona se uma dupla fiscalização à administração, desejável, por via de órgãos internos em termos de corporate governance, pode ser prosseguida com este poder do representante do Estado.

O regime da LRT condiciona bastante a autonomia da pessoa colectiva RT face ao Estado. Enunciam-se alguns poderes de tutela e fiscalização:

a) A homologação pelo membro do Governo responsável

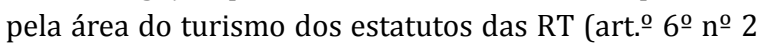
da LRT);

b) A autorização, pelos membros do Governo das áreas das finanças e do turismo, da aquisição, locação financeira ou alienação de bens imóveis e a aceitação de doações, heranças ou legados (art.o 6으뭉);

c) A aprovação prévia pelo membro do Governo responsável pela área do turismo, no prazo de 90 dias após a sua receção, do plano anual e plurianual de 
atividades, do orçamento, da conta de gerência e do relatório de atividades (art.o 6oㅡㄴ 4 );

d) 0 poder de ordenar a realização de inquéritos, sindicâncias, inspecções e auditorias aos serviços das entidades regionais de turismo, designadamente através da Inspeção -Geral de Finanças (art. ํㅜㅇㅡำ 7)

e) A necessidade de autorização para celebração de contratos de empréstimo às RT junto do sector financeiro, por despacho a exarar pelos membros do Governo responsáveis pelas áreas das finanças e do turismo (art.. $31^{\circ} \mathrm{n}^{\mathrm{o}} 4$ );

f) A alocação às RT das receitas provenientes, a nível central, de dotações que forem confiadas no Orçamento do Estado ao organismo central de turismo do Estado, o Turismo de Portugal, I. P. (TP) para prossecução do desenvolvimento do turismo regional e sub - regional, sendo esta a primeira fonte de financiamento prevista para as RT (art. $\left.\stackrel{0}{31^{\circ}} \mathrm{n}^{\mathrm{o}} \stackrel{1}{ }\right)$;

g) 0 condicionamento à existência de verbas previstas no orçamento do Estado e confiadas ao TP para prossecução do desenvolvimento do turismo regional e sub-regional (art.o $43^{\circ}$ ) para que se possam efetivar a celebração dos contratos-programa entre o TP e as entidades regionais de turismo, devendo os contratosprograma prever a obrigatoriedade do envio ao TP, dos documentos de prestação de contas, bem como de um dever genérico de informação e respetivas consequências para o incumprimento, em prazo a

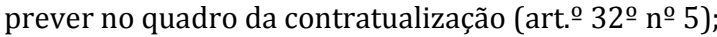

h) A aplicação às RT dos princípios e as regras da unidade de tesouraria do Estado (art. ${ }^{\circ} 30^{\circ}$ no ${ }^{2}$ ), onde se destaca a fiscalização e o julgamento das contas pelo Tribunal de Contas (art.․ 36욱.

Igualmente, o Estado na LRT procura racionalizar toda a organização interna (art. ${ }^{0} 23^{\circ}$ ), com regras de recrutamento de cargos dirigentes (art. ${ }^{\circ}$ 24우); condições de admissão, prestação e disciplina do trabalho (art.ํ 26으ำ 4); mapas de pessoal (art.o $27^{\circ}$ ), com regras apertadas quanto a encargos de pessoal que não podem exceder $50 \%$ da média das receitas correntes dos últimos três anos económicos, devendo reduzirem-se $5 \%$ adicionais, em cada ano dos três seguintes (art.ㅇ 29으을 2).

Este regime enfatizador de princípios de rigor, disciplina orçamental, unidade e eficiência da Administração acaba por assentar num apertado controlo tutelar do Estado sobre as $\mathrm{RT}$, tendo em vista cumprir as obrigações do memorando de entendimento com o FMI/UE. Tal não significa um reforço de princípios e boas práticas de corporate governance aplicáveis a uma pessoa coletiva autónoma de base associativa cujos valores se baseiam no empenho, compromisso, concertação e confiança de agentes públicos e privados interessados no planeamento, promoção e desenvolvimento do turismo numa determinada área territorial.

Na verdade, a informação e seu tratamento em sistemas, relatórios e comunicações operacionais fundadas num regime jurídico uniforme, claro e acessível aos interessados na sustentabilidade da organização (stakeholders) é uma variável fundamental do corporate governance. 0 regime das RT é omisso.

Não existe previsão que no sítio da internet da RT haja publicação do plano de actividades, do orçamento anual, do relatório anual de atividades e o relatório de contas e balanço de cada exercício submetidos à apreciação e aprovação da AG. Ou a aprovação desses documentos.

Não se prevê na página eletrónica da RT que sejam publicados os diplomas que os regulam, estatutos e regulamentos internos; composição dos órgãos sociais e respectiva remuneração; distribuição das dotações do orçamento de Estado e respetivos critérios; os contratosprograma realizados e as previsões de receita; custos e o

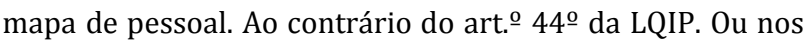
art. ${ }^{\circ}$ S $43^{\circ}$ no 3 e 53ำ da LQEP em termos de obrigação e transparência pública.

$\mathrm{Na}$ atual sociedade da informação, tão vital para os sistemas de turismo, as palavras internet e Administração eletrónica não constam da LRT. É uma perspectiva empobrecedora para uma boa governação das RT.

\section{Conclusões Finais.}

a) 0 corporate governance é um instrumento sistemático de análise de eficiência e robustez das organizações, dada a sua perspectiva transversal e homogeneizadora, tendo interesse e utilidade para a sua aplicação a organizações de turismo com composição mista de interesses públicos e privados;

b) As RT portuguesas podem definir-se como associações públicas para fins de planeamento e promoção turística, numa cooperação entre o Estado, municípios e entidades privadas num determinado território. Esta natureza especial e híbrida, simultaneamente institucional, territorial e empresarial não permite inserção num quadro global e sistémico uniforme de vinculações constitucionais e legais administrativas, o que traduz forte fragilidade em sede de princípios e práticas de corporate governance;

c) Os requisitos de boa governação de organizações em turismo dependem de alguma durabilidade, perenidade de estruturas, normalização de processos, consensos público-privados com acordos de longo prazo ou de préplaneamento entre entidades públicas e privadas;

d) A existência de mecanismos de financiamento anualizados baseados em contratos-programa e dotações anuais do Orçamento de Estado sem mecanismos auto-referenciais ligados às receitas turísticas geradas na região, enquanto receitas próprias, não permitem tal estabilidade ainda que os municípios sejam obrigados a um tempo de permanência mínima de 5 anos nas RT;

e) A governação das RT não prevê alinhamentos de informação através de elementos comuns e sistémicos fundamentais de auto- governo (ex: planos, orçamentos, contas, regulamentos internos) entre órgãos administrativos, de fiscalização e consultivos e deveres de cooperação reforçados; 
f) A criação na RT de um órgão (Conselho de Marketing) em assuntos especializados (promoção turística), de natureza ratificadora (aprovação de um plano de marketing) e consultiva (emissão de pareceres) confunde a natureza do órgão e sem remuneração aos seus membros, não cumpre imperativos constitucionais e legais de profissionalização de gestão, racionalidade técnica e eficiência administrativa;

g) A intervenção do Estado no órgão associativo mais importante da RT, pela sua natureza deliberativa e eletiva de outros órgãos (a Assembleia Geral) pode ter, pelo seu voto, a capacidade de gerar maiorias. Esta qualidade, assim como a sujeição pela RT a amplos poderes de tutela do Estado em sede de homologação de estatutos, autorização na aquisição e alienação de bens imóveis, celebração de contratos de empréstimo, aprovação prévia do plano de actividades, orçamento e conta de gerência cumpre objetivos constitucionais de unidade administrativa e eficácia no controlo da despesa pública, mas contraria princípios constitucionais vinculantes de democracia participativa, descentralização e autonomia administrativa que são relevantes num sistema de governação em turismo.

h) As RT estão ausentes da Administração Eletrónica quanto à publicação vinculativa de elementos fundamentais de auto-governo (estatutos, planos, contas, relatórios de actividade) na internet e na sua página eletrónica, o que constitui desvalorização de princípios de transparência, acessibilidade de informação e envolvência público-privada que constituem estímulos muito importantes de corporate governance aplicáveis a organizações de turismo.

Pelo que se conclui que a análise de corporate governance é um instrumento útil e eficaz à análise da qualidade normativa dos sistemas de governação das organizações público-privadas e dos seus princípios, de racionalidade e eficiência de gestão, mas também democráticos de sua organização e funcionamento. Para que se cumpram os objetivos do Estado de Direito Democrático previstos no art. $2^{\circ}$ da CRP. As RT de 2013 valorizaram mais os princípios de unidade e eficácia da Administração do que os de autonomia, democracia participativa e transparência.

\section{Referências}

Antunes, A.F. (2011). 0 governo das associações civis. In P. Câmara, G. F. Dias, R. O. Neves, D. C. Gonçalves, J. F. Gomes, A. Figueiredo et al. (Eds.), O governo das organizações - a vocação universal do corporate governance (pp.503-558). Coimbra: Almedina.

Brandão, P., Baldi, M., \& Alban, M. (2014). Descentralização da gestão pública do turismo brasileiro; análise da participação dos atores privados no Conselho Nacional de Turismo. Tourism and Management Studies, 10 (Special Issue), 193-199.

Burns P. (2004). Tourism planning- a third way. Annals of Tourism Research, 31 (1), 24-43.

Câmara, P. (2011). Vocação e influência universal do corporate governance. In P. Câmara, G. F. Dias, R. O. Neves, D. C. Gonçalves, J. F. Gomes, A. Figueiredo et al. (Eds.), O governo das organizações - a vocação universal do corporate governance (p. 13-42). Coimbra: Almedina.

Clarke, J. (2004). Trade associations: an appropriate channel for developing sustainable practices in SME. Journal of Sustainable Tourism, 12 (3), 195- 208.
Decrop, A.( 2004). Trustworthiness in qualitative tourism research. In J. Phillimore \& L. Goodson (Eds.), Qualitative research in tourism: Ontologies, epistemologies and methodologies (pp.156-169). Londres: Routledge.

De Falco, S., \& Renzi, A. (2007). Agency Theory, Stewardship Theory and Residual Right: logics and interpretative models. Revista Encontros Científicos, Tourism Management Studies, 3, 27-41.

Farinho, D.S. (2011). Alguns problemas de governo fundacional de uma perspectiva normativa-orgânica. In P. Câmara, G. F. Dias, R. O Neves, D. C. Gonçalves, J. F. Gomes, A. Figueiredo et al. (Eds.), O governo das organizações - a vocação universal do corporate governance (p. 583-669). Coimbra: Almedina.

Fernández, J.M., Jimenéz, E.M., \& Menéndez J.P. (2004). Derecho Público del Turismo. Cizur Menor: Aranzadi.

Freeman, R. (1984). Strategic management: a stakeholder approach. Massachusetts: Sage.

Gabardo, E. (2003). Eficiência e legitimidade do estado, uma análise das estruturas simbólicas do direito político. Tamboré: Editora Manole, Ltda.

Giotart, J.P., \& Balfet, M. (2007). Management du tourisme territoires, systèmes de production et stratégies (2ª edição). Paris Pearson Education France.

Lomba, P., \& Lino, D. (2011). Democratizar o governo das empresas públicas: o problema do duplo grau de agência. In In P. Câmara, G. F. Dias, R. O. Neves, D. C. Gonçalves, J. F. Gomes, A. Figueiredo et al. (Eds.), O governo das organizações - a vocação universal do corporate governance (pp.683-719). Coimbra: Almedina.

Machado, V. (2010). Direito e Turismo como instrumentos de poderos Territórios Turísticos. Santo Tirso: Editorial Novembro.

Medraño, M., Peñalver, F., \& Peñalver, A. (2013). Gestión económica para el buen gobierno corporativo en las entidades de economía social. In Proceedings TMS International Conference 2012: Vol. 4. Strategic Management, Entrepreneurship and Innovation, (pp. 11671182). Faro: Universidade do Algarve.

Memorando de Entendimento entre o Estado Português, o Banco Central Europeu, o Fundo Monetário Internacional e a Comissão de 17 de Maio de 2011. Acedido em 21 de Março, 2015 em http://www.portugal.gov.pt/media/371372/mou_pt_20110517.pdf

Miranda, J. (1988). As associações públicas no Direito Português. Separata da Revista da Faculdade de Direito de Lisboa (pp. 69-103). Lisboa: Faculdade de Direito da Universidade de Lisboa.

Moreira, V. (2002). Administração Pública e Associações Públicas. Coimbra: Coimbra Editora.

Moreira, V. (2005). As regiões de turismo e a administração regional do estado. Boletim da Faculdade de Direito da Universidade de Coimbra, LXXI, 21-56.

Oliveira, A.F. (2011). 0 governo dos órgãos de soberania. In P. Câmara, G. F. Dias, R. O. Neves, D. C. Gonçalves, J. F. Gomes, A Figueiredo et al. (Eds.), O governo das organizações - a vocação universal do corporate governance (p. 721-768). Coimbra: Almedina. Organização para a Cooperação e Desenvolvimento Económico (OCDE) (2004). Principles of corporate governance. Acedido em 15 de Março, 2015, em http://www.oecd.org/corporate/ca/ corporategovernanceprinciples/31557724.pdf

Pavlovich, K. (2003). The evolution and transformation of a tourism destination network: the Waitomo Caves, New Zealand. Tourism Management, 24, 203-216.

Pereira, M.N. (2007). Introdução ao Direito e às Obrigações (3ª edição). Coimbra: Almedina.

Py P. (1996). Droit du Tourisme. Paris: Dalloz.

Saixena, G. (2005). Relationships, networks and the learning regions: case evidence from the Peak District National Park. Tourism Management, 26, 277-289.

Torres, C. (2003). Regiões de Turismo. Lisboa: ANRET.

Submetido: 12.06 .2014

Aceite: 24.11.2014 